\title{
Genetic characterization of parthenogenic Fasciola sp. in Japan on the basis of the sequences of ribosomal and mitochondrial DNA
}

\author{
T. ITAGAKI I*, M. KIKAWA ${ }^{1}$, K. SAKAGUCHI ${ }^{1}$, J. SHIMO ${ }^{1}$, K. TERASAKI ${ }^{2}$, \\ T. SHIBAHARA ${ }^{3}$ and K. FUKUDA ${ }^{4}$ \\ ${ }^{1}$ Laboratory of Veterinary Parasitology, Faculty of Agriculture, Iwate University, Ueda 3-18-8, Morioka 020-8550, Fapan \\ ${ }^{2}$ St Mary's Funior College, Kurume 830-8558, Fapan \\ ${ }^{3}$ Division of Laboratory Animal Science, Research Center for Bioscience and Technology, Tottori University, \\ Yonago 683-8503, Fapan \\ ${ }^{4}$ Center for Laboratory Animal Science, National Defense Medical College, Tokorozawa 359-8513, fapan
}

(Received 25 March 2005; revised 9 May 2005; accepted 9 May 2005)

\section{SUMMARY}

Accurate identification of aspermic Fasciola forms in Japan remains difficult because of their morphological variations. In order to characterize the forms genetically, nucleotide sequences of ribosomal internal transcribed spacer (ITS1 and ITS2) and mitochondrial cytochrome c oxidase I (COI) and NADH dehydrogenase I (NDI) genes in 34 liver flukes from 16 prefectures in Japan were analysed. Two major forms represented by Fsp 1 and Fsp 2 had sequences identical to or closely resembling those of $F$. hepatica and $F$. gigantica, respectively, in all the 4 DNA markers and were mainly distributed in northern and eastern-western parts of Japan, respectively. Fsp 1 and Fsp 2 would have been introduced into Japan with infected cattle of 2 distinct lineages via the Korean Peninsula and spread through limited parts of Japan (northern and eastern-western parts) together with the movement of each cattle lineage. The Japanese form (Fsp 1/2), which showed heterozygosity in ribosomal DNA and Fsp 2 haplotype in mitochondrial DNA, may have originated in interspecific cross hybridization between paternal $F$. hepatica and maternal $F$. gigantica.

Key words: Fasciola sp., Japan, parthenogenesis, haplotype, ITS1, ITS2, COI, NDI, genetic characterization.

\section{INTRODUCTION}

The two species commonly recognized as the causative agents of fascioliasis in domestic animals and humans are Fasciola hepatica and F. gigantica. $F$. hepatica mainly occurs in Europe, Americas and Oceania, while $F$. gigantica is distributed in Africa and Asia (Torgerson and Claxton, 1999). Although the two species are classified by morphological characters, especially body length and width, it is difficult accurately to discriminate between the two species because of many variations in size depending on such factors as the age of the flukes, the species of host and the technical difficulty in fixation of the flukes (Kendall, 1965). The Fasciola species in Japan had been believed to be $F$. hepatica until Watanabe and Iwata (1954) raised doubt concerning the species. Their report motivated us to carry out research to identify the Japanese species of Fasciola. As a result, it has become clear that Japanese Fasciola species include worms morphologically resembling $F$. hepatica, $F$. gigantica and their intermediate forms

\footnotetext{
* Corresponding author: Laboratory of Veterinary Parasitology, Faculty of Agriculture, Iwate University, Ueda 3-18-8, Morioka 020-8550, Japan. Tel and Fax: +81 19621 6219. E-mail: itagaki@iwate-u.ac.jp
}

and that they have ecological characters resembling $F$. hepatica more than $F$. gigantica (Watanabe and Iwata, 1954; Itagaki and Akane, 1959; Oshima, Akahane and Shimazu, 1968; Akahane, Harada and Oshima, 1970). In addition, Fasciola species in Japan has been found to have cytogenetical characteristics differing from those of $F$. hepatica and $F$. gigantica. The Japanese forms include worms with 20 or 30 chromosomes corresponding to diploid and triploid sets and with 20/30 mosatic ploidy, and they are meiotically dysfunctional and aspermic (Moriyama, Tsuji and Seto, 1979; Sakaguchi, 1980), while $F$. hepatica and $F$. gigantica are spermic diploid and meiotically functional (Sanderson, 1953; Reddy and Subramanyam, 1973). Aspermic diploids and triploids in Japan had univalent chromosomes in primary oocytes, suggesting the potential of parthenogenesis (Terasaki et al. 2000). From these findings, it is still difficult accurately to identify Japanese Fasciola species.

Molecular genetic approaches based on DNA analysis have been employed to solve the problems of identification and genetic characterization of morphologically similar parasites, including Fasciola species (Blair and McManus, 1989; Adlard et al. 1993; McManus and Bowles, 1996). There have been studies on genetic characterization of Fasciola 
species in Japan based on ribosomal and mitochondrial DNA (Hashimoto et al. 1997; Itagaki et al. 1998; Itagaki and Tsutsumi, 1998). Hashimoto et al. (1997) and Itagaki et al. (1998) proved that a Japanese form was composed of flukes genetically identical to F. gigantica, whereas Itagaki and Tsutsumi (1998) showed the occurrence of those resembling $F$. hepatica and $F$. gigantica. These differences probably result from the small numbers of samples analysed and the lack of information on divergence of ribosomal DNA and that of mitochondrial DNA. In order accurately to characterize the Japanese Fasciola forms, we analysed the nucleotide sequences of ribosomal ITS1 and ITS2 and mitochondrial NDI and COI genes using 34 Fasciola samples collected in 16 prefectures of Japan.

\section{MATERIALS AND METHODS}

\section{Fasciola individuals and chromosome observation}

Thirty-four adults of Fasciola sp. were obtained from the bile ducts of infected cattle and sika deer (Cervis nippon centralis and C. n. ezoensis) in 16 different prefectures of Japan and kept at $-80^{\circ} \mathrm{C}$ or in $70 \%$ ethanol until DNA extraction. In some of the flukes, a small piece of the testis was cut off and fixed in freshly prepared ethanol-acetic acid $(3: 1)$ before freezing or fixation with $70 \%$ ethanol, and chromosomes were observed by using a squashing method (Snow, 1963). F. hepatica and $F$. gigantica that had been precisely identified by morphological features, including ratio of body length and width and the presence of sperm within the vesicula seminalis, were used for comparing degrees of DNA divergence. The $F$. hepatica used was from Uruguay (2 specimens), Australia (2) and Northern Ireland (2), and the $F$. gigantica used were from Zambia (6), Thailand (2) and Indonesia (3).

\section{$D N A$ extraction and amplification}

Total DNA was extracted from individual flukes by using an E.Z.N.A. mollusk DNA kit (Omega Bio-tek, Doraville, USA). DNA fragments of each target region were amplified by PCR using 1.25 units of Taq polymerase (Promega, Madison, USA), $0.4 \mathrm{~mm}$ each of dATP, dTTP, dCTP and dGTP, $2 \mathrm{mM} \mathrm{MgCl}_{2}$, each primer set $(50 \mathrm{pmol} / 25 \mu$ l reaction mixture), and PCR buffer. The primer sets used to amplify the fragments were Ita 10 (5'-AAGGATGTTGCTTTGTCGTGG-3') and Ita 2 (5'GGAGTACGGTTACATTCACA-'3) for NDI, Ita 8 (5'-ACGTTGGATCATAAGCGTGT-3') and Ita 9 (5'-CCTCATCCAACATAACCTCT-3') for COI, ITS1-F (5'-TTGCGCTGATTACGTCCCTG-3') and ITS1-R (5'-TTGGCTGCGCTCTTCATCGAC-3') for ITS1, and ITS2-F (5'-TGTGTCGATGAAGAGCGCAG-3') and
ITS2-R (5'-TGGTTAGTTTCTTTTCCTCCGC-3') for ITS2. Reaction cycles consisted of an initial denaturing step at $94^{\circ} \mathrm{C}$ for $90 \mathrm{sec}$, followed by 30 cycles at $94^{\circ} \mathrm{C}$ for $90 \mathrm{sec}, 55^{\circ} \mathrm{C}$ for $90 \mathrm{sec}$ and $72{ }^{\circ} \mathrm{C}$ for $120 \mathrm{sec}$ with a final extension at $72^{\circ} \mathrm{C}$ for $10 \mathrm{~min}$ using GeneAmp PCR Systems 2400 and 2700 (Applied Biosystems, 'Tokyo, Japan). PCR products were precipitated with ethanol/sodium acetate and dissolved in MilliQ water.

\section{Sequencing analysis}

PCR fragments were directly sequenced using ABI Prism Big Dye terminator v. 1.0 and v. 3.0 ready reaction cycle sequencing kits (Applied Biosystems) with the use of an additional primer, Ita 4 (5'CTATAACCAGTCATACT-3'), for ND1 together with the same primers as those used in PCR. At least 2 fragments amplified for individual flukes were sequenced for each target region in both directions using forward and reverse primers. The sequencing reactions were run on a PE Applied Biosystems 310 or 3100 automated sequencer. The sequence data were aligned by Clustal X program v. $1.53 \mathrm{~b}$ (Thompson et al. 1997). Phylogenetic analyses were conducted by neighbour-joining (NJ) and maximum parsimony (MP) using PAUP 4.0b10 (Swofford, 2001) with a lung fluke, Paragonimus westermani (Accession no. AF219379) designed as an outgroup. All characters were run unordered and equally weighted. Alignment gaps were treated as missing data. A heuristic search with tree-bisection-reconnection (TBR)-branch swapping was used in MP analysis to infer the shortest trees. The length, consistency index excluding uninformative characters (C.I.) and retention index (R.I.) of the most parsimonious trees were recorded. A bootstrap analysis (using 1000 replicates) was conducted using heuristic searches and TBR branch swapping with the MulTrees option in order to determine the relative support for clades of the consensus tree.

\section{RESULTS}

\section{Ploidy}

Chromosomes were observed in 12 of the 34 Japanese flukes. The number of chromosomes was counted in well-spread primary spermatocytes. Eleven flukes were found to have 30 univalent chromosomes $(3 \mathrm{n}=30$, triploid), and one had 20 univalent chromosomes $(2 \mathrm{n}=20$, diploid)(Table 1$)$.

\section{Haplotype from ITS1 and ITS2 sequences}

The sequences of the ITS1 region in Fasciola specimens (Accession numbers AB207139-AB207147) consisted of $600 \mathrm{bps}$ including complete ITS1, 
Table 1. Haplotype and ploidy of parthenogenic Fasciola sp. in Japan

\begin{tabular}{|c|c|c|c|c|c|c|}
\hline \multirow{2}{*}{$\begin{array}{l}\text { Specimen } \\
\text { code\# }\end{array}$} & \multirow[b]{2}{*}{ Locality } & \multirow[b]{2}{*}{ Ploidy } & \multicolumn{4}{|c|}{ Haplotype } \\
\hline & & & ITS1 & ITS2 & NDI & $\mathrm{COI}$ \\
\hline 1 & Hokkaido & $3 n$ & Fsp 1 & Fsp 1 & Fsp 1 & Fsp 1 \\
\hline 2 & Hokkaido & ND & Fsp 1 & Fsp 1 & Fsp 1 & Fsp 1 \\
\hline 3 & Aomori & $3 n$ & Fsp 1 & Fsp 1 & Fsp 1 & Fsp 1 \\
\hline 4 & Aomori & $3 n$ & Fsp 1 & Fsp 1 & Fsp 1 & Fsp 1 \\
\hline 5 & Iwate & $3 n$ & Fsp 1 & Fsp 1 & Fsp 1 & Fsp 1 \\
\hline 6 & Iwate & $3 n$ & Fsp 1 & Fsp 1 & Fsp 1 & Fsp 1 \\
\hline 7 & Iwate & $3 n$ & Fsp 1 & Fsp 1 & Fsp 1 & Fsp 1 \\
\hline 8 & Tochigi & $3 n$ & Fsp 1 & Fsp 1 & Fsp 1 & Fsp 1 \\
\hline 9 & Tochigi & $3 n$ & Fsp 1 & Fsp 1 & Fsp 1 & Fsp 1 \\
\hline 10 & Saitama & ND & Fsp 2 & Fsp 2 & Fsp 2 & Fsp 2 \\
\hline 11 & Saitama & ND & Fsp 2 & Fsp 2 & $F s p 2$ & Fsp 2 \\
\hline 12 & Nagano & ND & Fsp 2 & Fsp 2 & Fsp 2 & Fsp 2 \\
\hline 13 & Nagano & ND & Fsp 2 & Fsp 2 & Fsp 2 & Fsp 2 \\
\hline 14 & Nagano & ND & Fsp 2 & Fsp 2 & Fsp 2 & Fsp 2 \\
\hline 15 & Nara & $3 n$ & Fsp 1 & Fsp 1 & Fsp 1 & Fsp 1 \\
\hline 16 & Hyogo & ND & Fsp 2 & Fsp 2 & Fsp 2 & Fsp 2 \\
\hline 17 & Hyogo & ND & Fsp 2 & Fsp 2 & Fsp 2 & Fsp 2 \\
\hline 18 & Hiroshima & $2 n$ & Fsp $1 / 2$ & Fsp $1 / 2$ & Fsp 2 & Fsp 2 \\
\hline 19 & Hiroshima & ND & Fsp 2 & Fsp 2 & Fsp 2 & Fsp 2 \\
\hline 20 & Hiroshima & ND & Fsp 2 & Fsp 2 & Fsp 2 & Fsp 2 \\
\hline 21 & Tottori & ND & Fsp 1 & Fsp 1 & Fsp 1 & Fsp 1 \\
\hline 22 & Tottori & ND & Fsp 1 & Fsp 1 & Fsp 1 & Fsp 1 \\
\hline 23 & Tokushima & $3 n$ & Fsp 2 & Fsp 2 & Fsp 2 & Fsp 2 \\
\hline 24 & Tokushima & $3 n$ & Fsp 2 & Fsp 2 & Fsp 2 & Fsp 2 \\
\hline 25 & Kochi & ND & Fsp 2 & Fsp 2a & Fsp 2 & Fsp 2 \\
\hline 26 & Kochi & ND & Fsp 2 & Fsp 2a & Fsp 2 & Fsp 2 \\
\hline 27 & Saga & ND & Fsp 2 & Fsp 2 & Fsp 2 & Fsp 2 \\
\hline 28 & Saga & ND & Fsp 2 & Fsp 2 & Fsp 2 & Fsp 2 \\
\hline 29 & Nagasaki & $\mathrm{ND}$ & Fsp 2 & Fsp 2 & Fsp 2 & Fsp 2 \\
\hline 30 & Nagasaki & ND & Fsp 2 & Fsp 2 & Fsp 2 & Fsp 2 \\
\hline 31 & Kumamoto & ND & Fsp 1 & Fsp 1 & Fsp 2 & Fsp 2 \\
\hline 32 & Kumamoto & ND & Fsp 2 & Fsp 2 & Fsp 2 & Fsp 2 \\
\hline 33 & Kagoshima & ND & $F \operatorname{sp} 1 / 2$ & $F \operatorname{sp~1/2}$ & Fsp 2 & Fsp 2 \\
\hline 34 & Kagoshima & ND & Fsp 1/2 & Fsp 1/2 & Fsp 2 & Fsp 2 \\
\hline
\end{tabular}

' $2 n$ ' and ' $3 n$ ' mean diploid and triploid, respectively.

$\mathrm{ND}$, no data.

partial $18 \mathrm{~S}$ and $5 \cdot 8 \mathrm{~S}$ rDNA and had 6 variable nucleotide positions of which 1 was located in $18 \mathrm{~S}$ and 5 were located in ITS1. The sequences of $F$. hepatica and $F$. gigantica differed at the 6 positions. Japanese flukes showed 3 different sequences (haplotypes) represented by Fsp 1, Fsp 2 and Fsp $1 / 2$ which had nucleotides identical to $F$. hepatica and $F$. gigantica and those overlapped between the two species, respectively (Table 2). The 505-bp or 506-bp sequence of the ITS2 region included complete ITS2, partial $5 \cdot 8 \mathrm{~S}$ and $28 \mathrm{~S}$, and 8 nucleotide positions (including 1 gap) within the sequence were variable among individuals of Fasciola spp. (Accession nos. AB207148-AB207153). Japanese flukes were divided into 4 haplotypes (Fsp 1, Fsp 2, Fsp 2a, Fsp 1/2) based on the nucleotides at the 7 sites. Fsp 1 and Fsp 2 were identical or very similar to sequences of $F$. hepatica and $F$. gigantica, respectively. Fsp 2a differed from Fsp 2 in only 1 nucleotide site (331). Fsp 1/2 had nucleotides overlapped between Fsp 1 and Fsp 2 at 5 sites (307, 318,
$331,370,376)$ and the same nucleotides as Fsp 1 at 2 sites $(424,434)$. The number of Japanese flukes that showed the haplotypes of Fsp 1, Fsp 2 including Fsp 2a and Fsp 1/2 in both ITS1 and ITS2 regions were 13,18 and 3 , respectively. All of the flukes obtained from Hokkaido, Aomori, Iwate and Tochigi Prefectures in the northern part of Japan showed Fsp 1 in both regions, whereas most of the flukes from the western (Kagoshima) to eastern (Saitama) parts of Japan showed Fsp 2 (Fig. 1). Eleven triploid flukes showed either Fsp 1 or Fsp 2, and 1 diploid showed Fsp 1/2 (Table 1).

\section{Haplotype from $C O I$ and NDI sequences}

Partial COI sequence ( $438 \mathrm{bp}$ ) and NDI sequence (535 bp) were determined for 51 Fasciola individuals used and included 62 and 68 variable sites, respectively (Accession nos. AB207170-AB207183, AB207103, AB207154-AB207169). Although intraspecific variability in COI and NDI sequences was 
Table 2. Comparison of the nucleotides at variable sites in the ITS1 and ITS2 regions of Fasciola spp.

\begin{tabular}{|c|c|c|c|c|c|c|c|c|c|c|c|c|c|c|c|c|}
\hline \multirow[b]{2}{*}{ Species } & \multirow{2}{*}{$\begin{array}{l}\text { Locality and } \\
\text { haplotype }\end{array}$} & \multicolumn{6}{|c|}{ Sites of ITS1 region } & \multicolumn{8}{|c|}{ Sites of ITS2 region } & \multirow{2}{*}{$\begin{array}{l}\text { No. of } \\
\text { worms }\end{array}$} \\
\hline & & 48 & 175 & 265 & 359 & 437 & 457 & 307 & 318 & 331 & 370 & 376 & 384 & 424 & 434 & \\
\hline \multirow[t]{3}{*}{ F. hepatica } & Uruguay & $\mathrm{T}$ & $\mathrm{C}$ & $\mathrm{A}$ & $\mathrm{C}$ & $\mathrm{T}$ & $\mathrm{C}$ & $\mathrm{T}$ & $\mathrm{T}$ & $\mathrm{T}$ & $\mathrm{C}$ & $\mathrm{C}$ & $\mathrm{T}$ & $\mathrm{T}$ & $\mathrm{G}$ & 2 \\
\hline & Australia & $\mathrm{T}$ & $\mathrm{C}$ & $\mathrm{A}$ & $\mathrm{C}$ & $\mathrm{T}$ & $\mathrm{C}$ & $\mathrm{T}$ & $\mathrm{T}$ & $\mathrm{T}$ & $\mathrm{C}$ & $\mathrm{C}$ & $\mathrm{C}$ & $\mathrm{T}$ & $\mathrm{G}$ & 2 \\
\hline & N. Ireland & $\mathrm{T}$ & $\mathrm{C}$ & $\mathrm{A}$ & $\mathrm{C}$ & $\mathrm{T}$ & $\mathrm{C}$ & $\mathrm{T}$ & $\mathrm{T}$ & $\mathrm{T}$ & $\mathrm{C}$ & $\mathrm{C}$ & $\mathrm{C}$ & $\mathrm{T}$ & $\mathrm{G}$ & 2 \\
\hline \multirow{3}{*}{$F$. gigantica } & Indonesia & $\mathrm{C}$ & $\mathrm{T}$ & $\mathrm{T}$ & $\mathrm{T}$ & $\mathrm{A}$ & $\mathrm{T}$ & $\mathrm{C}$ & $\mathrm{T}$ & $\mathrm{C}$ & $\mathrm{T}$ & $\mathrm{T}$ & $\mathrm{C}$ & - & $\mathrm{A}$ & 2 \\
\hline & Thailand & $\mathrm{C}$ & $\mathrm{T}$ & $\mathrm{T}$ & $\mathrm{T}$ & A & $\mathrm{T}$ & $\mathrm{C}$ & $\mathrm{T}$ & $\mathrm{C}$ & $\mathrm{T}$ & $\mathrm{T}$ & $\mathrm{C}$ & - & $\mathrm{A}$ & 2 \\
\hline & Zambia & $\mathrm{C}$ & $\mathrm{T}$ & $\mathrm{T}$ & $\mathrm{T}$ & A & $\mathrm{T}$ & $\mathrm{T}$ & $\mathrm{T}$ & $\mathrm{C}$ & $\mathrm{T}$ & $\mathrm{T}$ & $\mathrm{C}$ & - & A & 6 \\
\hline \multirow[t]{4}{*}{ Fasciola sp. } & Japan; Fsp 1 & $\mathrm{~T}$ & $\mathrm{C}$ & A & $\mathrm{C}$ & $\mathrm{T}$ & $\mathrm{C}$ & $\mathrm{T}$ & $\mathrm{T}$ & $\mathrm{T}$ & $\mathrm{C}$ & $\mathrm{C}$ & $\mathrm{C}$ & $\mathrm{T}$ & G & 13 \\
\hline & Japan; Fsp 2 & $\mathrm{C}$ & $\mathrm{T}$ & $\mathrm{T}$ & $\mathrm{T}$ & $\mathrm{A}$ & $\mathrm{T}$ & $\mathrm{C}$ & $\mathrm{C}$ & $\mathrm{C}$ & $\mathrm{T}$ & $\mathrm{T}$ & $\mathrm{C}$ & - & A & 16 \\
\hline & Japan; Fsp 2a & $\mathrm{C}$ & $\mathrm{T}$ & $\mathrm{T}$ & $\mathrm{T}$ & $\mathrm{A}$ & $\mathrm{T}$ & $\mathrm{C}$ & $\mathrm{C}$ & $\mathbf{T}$ & $\mathrm{T}$ & $\mathrm{T}$ & $\mathrm{C}$ & - & $\mathrm{A}$ & 2 \\
\hline & Japan; Fsp $1 / 2$ & $\mathrm{~T} / \mathrm{C}$ & $\mathrm{C} / \mathrm{T}$ & $\mathrm{A} / \mathrm{T}$ & $\mathrm{C} / \mathrm{T}$ & $\mathrm{T} / \mathrm{A}$ & $\mathrm{C} / \mathrm{T}$ & $\mathrm{T} / \mathrm{C}$ & $\mathrm{T} / \mathrm{C}$ & $\mathrm{T} / \mathrm{C}$ & $\mathrm{C} / \mathrm{T}$ & $\mathrm{C} / \mathrm{T}$ & $\mathrm{C}$ & $\mathrm{T}$ & $\mathrm{G}$ & 3 \\
\hline
\end{tabular}

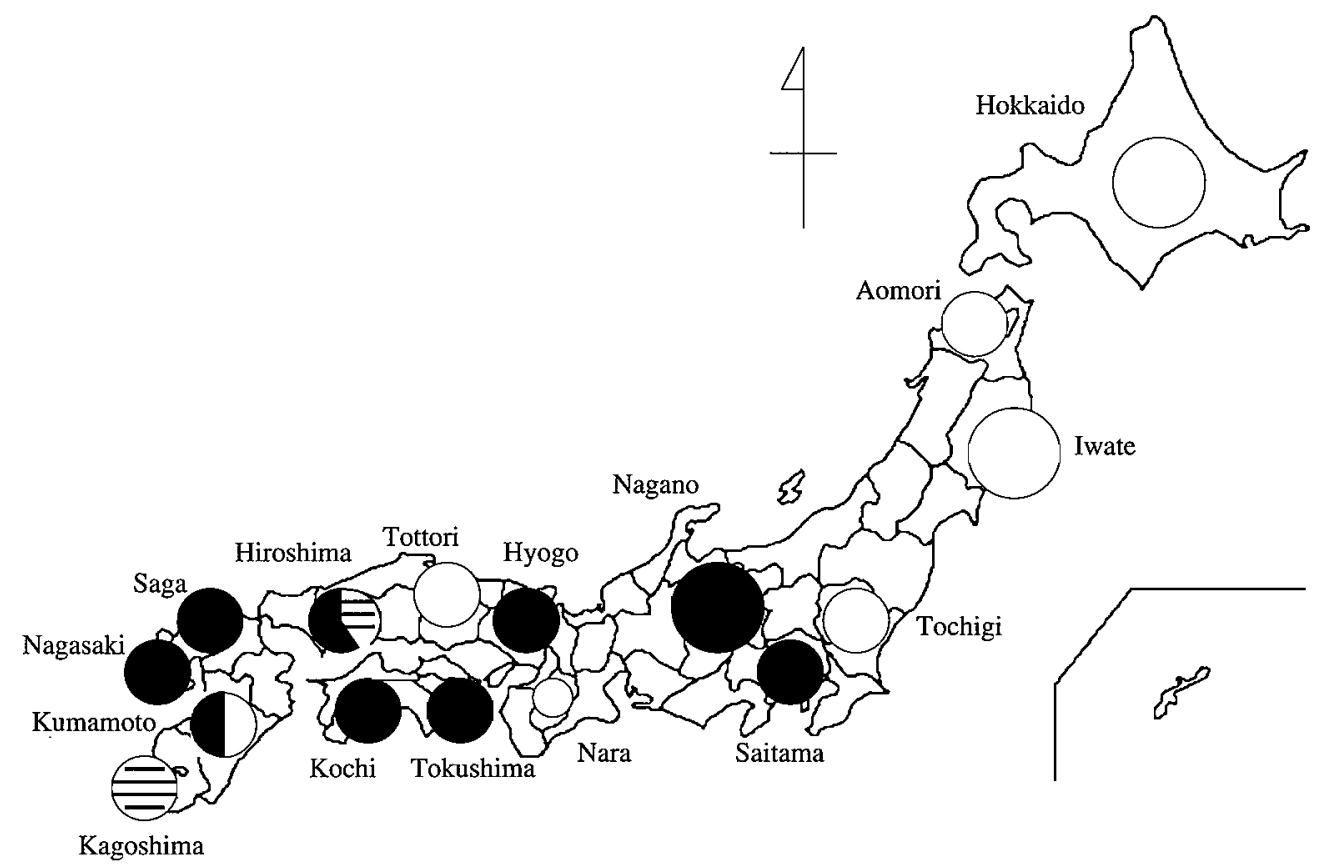

Fig. 1. Distribution of the haplotypes of Fasciola sp. in Japan. White, black and striped circles represent the haplotypes, Fsp 1, Fsp 2 and Fsp 1/2, respectively.

found in $F$. hepatica and $F$. gigantica, the degree of variability was higher in $F$. gigantica than in $F$. hepatica. Japanese specimens had either of 2 distinct sequences (haplotypes: Fsp 1, Fsp 2) in both COI and NDI. Fsp 1 and Fsp 2 differed from each other at 41 nucleotide positions within COI and at 45 sites within NDI. Fsp 1 was very similar to the sequence of $F$. hepatica in both COI and NDI, though no complete consistency was confirmed between the sequences. In contrast, Fsp 2 was similar to the sequence of $F$. gigantica, being more similar to the sequence of $F$. gigantica obtained from Indonesia and Thailand than from Zambia. Twelve of 34 flukes showed Fsp 1, and the other 22 showed Fsp 2. MP analysis resolved most parsimonious trees for COI (length $356 ; \mathrm{CI}=0.9270 ; \mathrm{RI}=0.9323$ ) and NDI (length 522; CI $=0.8966 ; \mathrm{RI}=0.8893$ )
(Fig. 2). Tree topologies from MP and NJ (not shown) analyses were consistent with each other in both sequence sets of COI and NDI. The individuals of $F$. hepatica and Fsp 1 belonged to the same clade, which clearly differed from the clade of $F$. gigantica and Fsp 2.

\section{DISCUSSION}

The haplotypes based on the sequences of ITS1, ITS2, COI and NDI showed that 2 major and 3 minor distinct forms of Fasciola occurred in Japan. Similarly, 3 different forms identified using isozyme patterns have been found in Japanese triploid Fasciola (Agatsuma et al. 1994), suggesting at least 3 origins of triploidy. Recently, Terasaki et al. (2000) have suggested that the most likely origin of triploid 
A

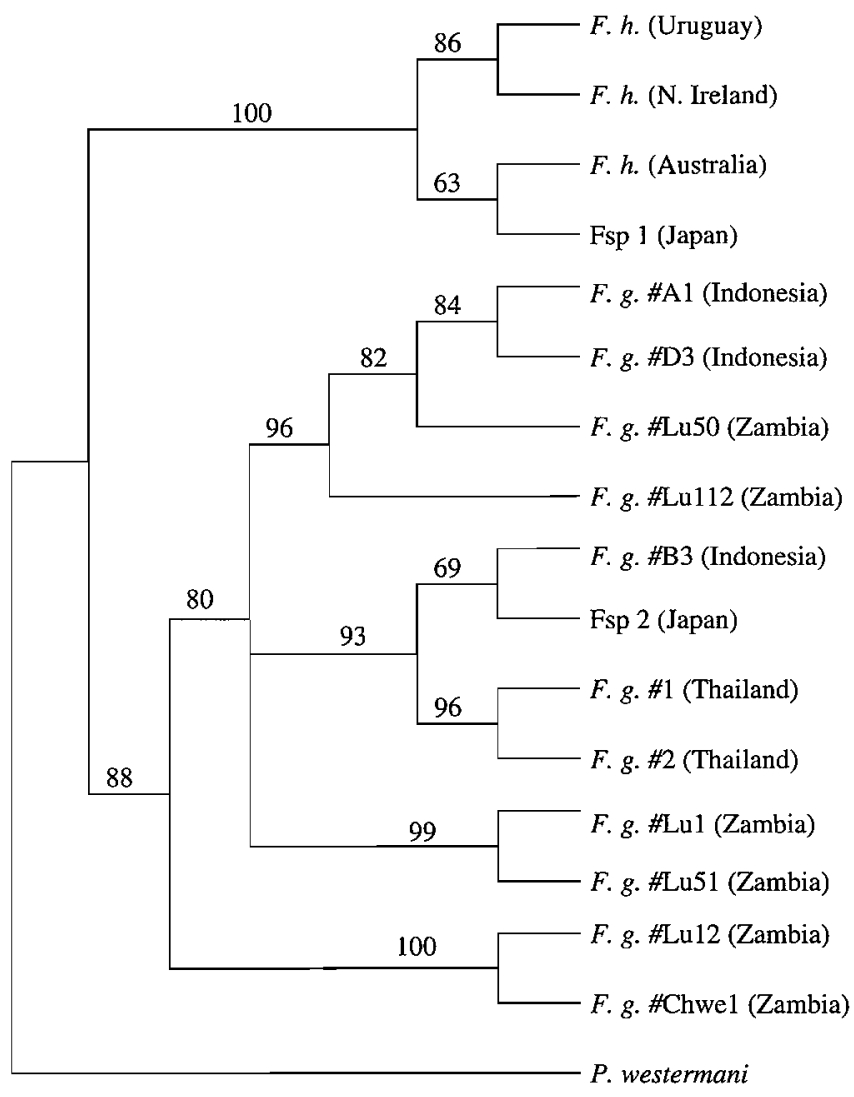

B

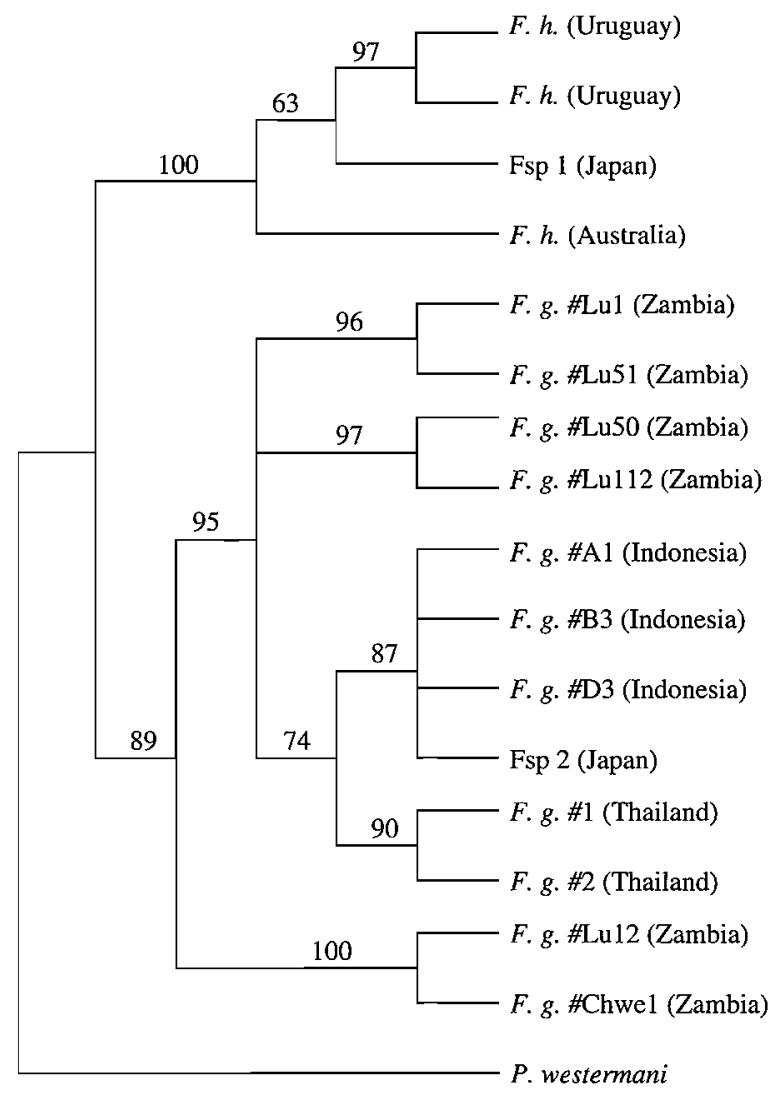

Fig. 2. Maximum parsimony trees of Fasciola spp. inferred from the nucleotide sequences of partial NDI (A) and COI (B). Fsp 1 and Fsp 2 show the haplotypes of Fasciola sp. in Japan. $F . h$. and $F$. g. show $F$. hepatica and $F$. gigantica, respectively. '\#' and parentheses represent code no. and locality of individual, respectively.

forms was the fusion of a sperm of a bisexual diploid $(F$. hepatica or $F$. gigantica) with an unreduced egg of a parthenogenetic diploid. According to this hypothesis, the triploid specimens (e.g., \#1) that showed the genotype of Fsp 1 ( $F$. hepatica type) in both ribosomal and mitochondrial DNA would be derived from hybridization between parental $F$. hepatica and parthenogenetic diploid ( $F$. hepatica type). In fact, parthenogenic diploid forms closely resembling $F$. hepatica in sequences of $\mathrm{rDNA}$ and mtDNA have been found in Korea (Itagaki et al., unpublished data). Similarly, the triploid individuals (e.g., \#23) with the genotype of Fsp 2 in both markers seem to be crossing progenies between $F$. gigantica and parthenogenic diploid ( $F$. gigantica type). On the other hand, the parthenogenic diploid appears to be directly derived from bisexual $F$. hepatica or $F$. gigantica populations (Terasaki et al. 2000). Furthermore, in most animal taxa, the acquisition of clonal reproduction may be a consequence of hybridization between sexual species (Dawley, 1989; Wilson and Hebert, 1992; Vrijenhoek, 1994). Most clonal lineages therefore contain a mixture of the nuclear genomes of the two or more sexual species (Avise, Quattro and Vrijenhoek, 1992). Thus, the aspermic diploid (\#18) that showed a heterozygous genotype (Fsp 1/2) in rDNA and Fsp 2 in mtDNA may have originated in interspecific cross-hybridization between paternal $F$. hepatica and maternal $F$. gigantica. This natural hybridization between the two bisexual Fasciola species has been also suggested by results of previous analyses (Itagaki and Tsutsumi, 1998; Agatsuma et al. 2000).

Although aspermic (parthenogenic) Fasciola is widely distributed in East and Southeast Asia (Terasaki, Akahane and Habe, 1982), the origin still remains unknown. However, parthenogenic Fasciola would not have originated in Japan as well as in Korea, since no bisexual Fasciola has been found in those countries. We have recently found that triploid individuals $100 \%$ identical to Fsp 2 in the sequences of not only I'TS1 but also mitochondrial COI and NDI with rapid base substitution were present in Vietnam, which is far from Japan (Itagaki et al., unpublished data). The origin of the triploid forms, however, is also not Vietnam, since no parthenogenic diploid has been found in Vietnam. These findings strongly suggest that the triploid forms with the genotype of Fsp 2 originated in a country other than Japan, Korea and Vietnam and rapidly spread among these countries with infected 
animals (probably domestic cattle). Molecular phylogeny using Fasciola individuals from other Asian counties is needed to elucidate the origin and route of spread throughout Asia of parthenogenic Fasciola forms.

Japanese native cattle were thought to have been introduced into Japan via the Korean Peninsula in about the second century AD (Mukai, 1989). In fact, Japanese and Korean native cattle consist of haplotypes very similar to each other in mtDNA sequences. Interestingly, only 2 of the haplotypes are major in Japan (Mannen et al. 2004). Furthermore, Fasciola forms that are completely identical to Fsp 1 and Fsp 2 in sequences of both rDNA and mtDNA occur in Korea (Itagaki et al., unpublished data). These findings strongly suggest that Fsp 1 and Fsp 2 invaded Japan with infected cattle and spread through limited parts of Japan together with the movement of the 2 haplotypes of cattle.

This study was supported in part by a Grant-in-Aid for Scientific Research (C) (no. 14560243) from the Ministry of Education, Culture, Sports, Science and Technology of Japan.

\section{REFERENCES}

Adlard, R. D., Barker, S. C., Blair, D. and Cribb, T. H. (1993). Comparison of the second internal transcribed spacer (ribosomal DNA) from populations and species of Fasciolidae (Digenea). International fournal for Parasitology 23, 423-425.

Agatsuma, T., Terasaki, K., Yang, L. and Blair, D. (1994). Genetic variation in the triploids of Japanese Fasciola species, and relationships with other species in the genus. Fournal of Helminthology 68, 181-186.

Agatsuma, T., Arakawa, Y., Iwagami, M., Honzako, Y., Cahyaningsih, U., Kang, S-Y. and Hong, S-J. (2000). Molecular evidence of natural hybridization between Fasciola hepatica and F. gigantica. Parasitology International 49, 231-238.

Akahane, H., Harada, Y. and Oshima, T. (1970). Patterns of variation of the common liver fluke (Fasciola sp.) in Japan. III. Comparative studies on the external form, size of egg and number of eggs in the uterus of fluke in cattle, goat and rabbit. Fapanese Fournal of Parasitology 19, 619-627 (in Japanese with English summary).

Avise, J. C., Quattro, J. M. and Vrijenhoek, R. C. (1992). Molecular clones within organismal clones: mitochondrial DNA phylogenies and the evolutionary histories of unisexual vertebrates. Fournal of Evolutionary Biology 26, 225-246.

Blair, D. and McManus, D. P. (1989). Restriction enzyme mapping of ribosomal DNA can distinguish between fasciolid (liver fluke) species. Molecular and Biochemical Parasitology 36, 201-208.

Dawley, R. M. (1989). An introduction to unisexual vertebrates. In Evolution and Ecology of Unisexual Vertebrates (ed. Dawley, R. M. and Bogart, J. P.), pp. 1-18. New York State Museum, Albany, New York.
Hashimoto, K., Watanobe, T., Liu, C. X., Init, I., Blair, D., Ohnishi, T. and Agatsuma, T. (1997).

Mitochondrial DNA and nuclear DNA indicate that the Japanese Fasciola species is $F$. gigantica. Parasitology Research 83, 220-225.

Itagaki, H. and Akane, S. (1959). Morphological study on the Japanese liver fluke, compared with the African specimens. The Bulletin of Azabu Veterinary College 6, 115-123.

Itagaki, T. and Tsutsumi, K. (1998). Triploid form of Fasciola in Japan: genetic relationships between Fasciola hepatica and Fasciola gigantica determined by ITS-2 sequence of nuclear rDNA. International Fournal for Parasitology 28, 777-781.

Itagaki, T., Tsutsumi, K., Ito, K. and Tsutsumi, Y. (1998). Taxonomic status of the Japanese triploid forms of Fasciola: comparison of mitochondrial ND1 and COI sequences with $F$. hepatica and $F$. gigantica. Fournal of Parasitology 84, 445-448.

Kendall, S. B. (1965). Relationships between the species of Fasciola and their molluscan hosts. Advances in Parasitology 3, 59-95.

Mannen, H., Kohno, M., Nagata, Y., Tsuji, S., Bradley, D. G., Yeo, J. S., Nyamsamba, D., Zagdsuren, Y., Yokohama, M., Nomura, K. and Amano, T. (2004). Independent mitochondrial origin and historical genetic differentiation in North Eastern Asian cattle. Molecular Phylogenetics and Evolution 32, 539-544.

McManus, D. P. and Bowles, J. (1996). Molecular genetic approaches to parasite identification: their value in diagnostic parasitology and systematics. International Fournal for Parasitology 26, 687-704.

Moriyama, N., Tsuji, M. and Seto, T. (1979). Three karyotypes and their phenotypes of Japanese liver flukes (Fasciola sp.). Fapanese Fournal of Parasitology 28, 23-33 (in Japanese with English summary).

Mukai, F., Tsuji, S., Fukazawa, K., Ohtagaki, S. and Nambu, Y. (1989). History and population structure of a closed strain of Japanese Black cattle. Fournal of Animal. Breeding and Genetics 106, 254-264.

Oshima, T., Akahane, H. and Shimazu, T. (1968). Patterns of the variation of the common liver fluke (Fasciola sp.) in Japan. I. Variations in the sizes and shapes of the worms and eggs. Fapanese fournal of Parasitology 17, 97-105 (in Japanese with English summary).

Reddy, P. V. and Subramanyam, S. (1973). Chromosome studies in the liver fluke, Fasciola gigantica Cobbold, 1856, from Andra Pradesh. Current Science 42, 288-291.

Sakaguchi, Y. (1980). Karyotype and gametogenesis of the common liver fluke, Fasciola sp., in Japan. Fapanese Fournal of Parasitology 29, 507-513.

Sanderson, A. R. (1953). Maturation and probable gynogenesis in the liver fluke, Fasciola hepatica L. Nature, London 172, 110-112.

Snow, R. (1963). Alcoholic hydrochloric acid-carmine as a stain for chromosomes in squash preparations. Stain Technology 38, 9-13.

Swofford, D. L. (2001). PAUP*. Phylogenetic analysis using parsimony and other methods ver. 4.0beta. Sinauer Associates, Sunderland, Massachussetts. 
Terasaki, K., Akahane, H. and Habe, S. (1982). The geographical distribution of common liver flukes (the Genus Fasciola) with normal and abnormal spermatogenesis. Fapanese Fournal of Parasitology 44, 223-231.

Terasaki, K., Noda, Y., Shibahara, T. and Itagaki, T. (2000). Morphological comparisons and hypotheses on the origin of polyploids in parthenogenetic Fasciola sp. Fournal of Parasitology 86, 724-729.

Thompson, J. D., Gibson, T. J., Plewniak, F., Jeanmougin, F. and Higgins, D. G. (1997). The Clustal X windows interface: flexible strategies for multiple sequence alignment aided by quality analysis tools. Nucleic Acid Research 24, 4876-4882.
Torgerson, P. and Claxton, J. (1999). Epidemiology and control. In Fasciolosis (ed. Dalton, J. P.), pp. 113-149. CABI Publishing, UK.

Vrijenhoek, R. C. (1994). Unisexuala fish: model systems for studying ecology and evolution. Annual Review of Ecology and Systematics 25, 71-96.

Watanabe, S. and Iwata, S. (1954). Fasciola species in Japan. Journal of Japan Veterinary Medical Association 7, 124-126 (in Japanese).

Wilson, C. C. and Hebert, P. D. N. (1992). The maintenance of taxon diversity in an asexual assemblage: an experimental analysis. Ecology 73, 1462-1472. 